\title{
From selection to registration, and beyond: Supporting the student in becoming a compassionate professional
}

\section{Hollie Hadwen ${ }^{1}$, Jane Harvey-Lloyd ${ }^{2}$, and Ruth Strudwick ${ }^{2}$}

\begin{abstract}
The National Health Service (NHS) Constitution aims to safeguard the underpinning principles and values of the NHS. Whilst employers are obligated to recruit staff whose values and behaviours align with those of the Constitution, Higher Education Institutions (HEIs) are also expected to select students who demonstrate an understanding of those values and behaviours and the potential to use them with their working practices. From the point of selection, HEIs assume a pivotal role in promoting and embedding those values and behaviours into curricula, and thus supporting individuals in the transition from student to professional. The purpose of this paper is to discuss how values-based practice has been embedded in undergraduate radiography education at one HEI. It describes how the HEI utilises values-based recruitment and selection processes, and explores the strategies employed to develop that foundation prior to entering practice placement. Key issues are discussed including the importance of acknowledging and valuing the early experiences of students prior to being socialised into the established culture of the diagnostic imaging department. The role of the lecturer in supporting the transition from student to compassionate professional cannot be underestimated. This is multi-faceted and acting as a professional role model to students is an essential part of the role whilst helping students to develop their own professional identity throughout the course.
\end{abstract}

Kewords: radiography; curriculum; compassion; role model; values; NHS

1. Lecturer, Diagnostic Radiography, University of Suffolk

2. Associate Professor, Diagnostic Radiography, University of Suffolk

Address for correspondence: h.hadwen@uos.ac.uk

Date of first (online) publication: 29th June 2020

78 J. of Practice Teaching \& Learning 17(2), pp.78-90. ๑ w\&b 


\section{Introduction}

The NHS Constitution aims to safeguard the underpinning principles and values of the NHS, emphasising the behaviours expected of all NHS staff (DH, 2015). It is a combination of patient/public and staff rights and pledges that the NHS is both responsible for and committed to achieving. The values are illustrated in Figure 1 below:

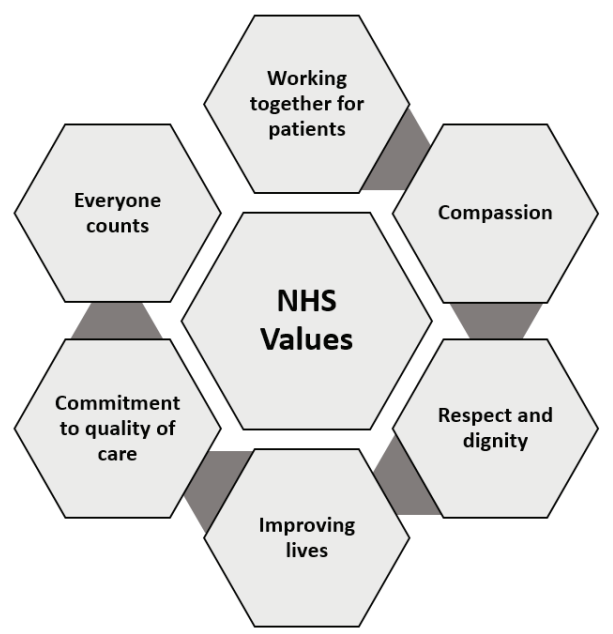

Figure 1: The NHS Values

The values are designed to underpin certain behaviours in staff which align to each of the values e.g. 'working together for patients' should instil a person-centred approach at all times, ensuring that service users are involved in every aspect of their treatment and that both service users and staff are empowered to speak up when things are not acceptable or errors are made.

As a result, all NHS employers are now obligated to recruit staff whose values and behaviours align with those of the constitution. Similarly, HEIs assume a fundamental role in promoting and embedding those values and behaviours into selection and recruitment strategies and curricula, thus supporting individuals in the transition from student to professional.

The foundation for values-based practice is explored and developed with students prior to entering their first practice placement, through lectures and discussion about caring for the service user and using case studies.

79 J. of Practice Teaching \& Learning 17(2), pp.78-90. ๑ wE-b 
Values-Based Practice (VBP) is the consideration of a patient's values in decision-making. By patient's values we mean the unique preferences, concerns and expectations each patient brings to a practice encounter which must be integrated into any decisions about the care of the patient. VBP is an approach that compliments evidence-based practice to ensure a holistic service. In essence, VBP takes into account and highlights what matters, and therefore is important to the patient (Fulford et al., 2012). Values-based curricula often combine the development of emotional intelligence and virtue ethics in order to enhance the development of compassionate care in nursing (Rankin, 2013; McLean, 2012).

The importance of early experiences on the course prior to being socialised into the established culture of the diagnostic imaging department is recognised alongside the need for lecturers to act as professional role models (Christiansen et al., 2015; Hendry, 2019). Staff members continue to support students in developing their professional identity over the three-year programme of study.

It is worthy of note that the term 'service user', as opposed to 'patient', has been used within this paper, as this more accurately reflects the population accessing imaging services e.g. well women attending for breast screening.

\section{Recruitment and selection}

Service users, practice partners, current students and lecturers collaboratively designed and implemented the following Multiple-Mini Interviews (MMIs):

- MMI Station 1: Communication with service users and carers. This station is specifically designed to assess the applicant's ability to quickly form a positive relationship with a service user. It focusses on their ability to actively listen and communicate effectively whilst demonstrating the NHS values of compassion, respect and dignity, and everyone counts.

- MMI Station 2: Universities and Colleges Admissions Service (UCAS) Personal Statement. This station explores the reasons why the applicant has chosen radiography as their potential profession and what skills and attributes they can evidence which underpins the NHS values of compassion, working together for patients and everyone counts.

80 J. of Practice Teaching \& Learning 17(2), pp.78-90. ๑ wE-b 
- MMI Station 3: Understanding the radiography profession. This station is always led by a practising radiographer who delves into the applicant's knowledge and understanding of the profession. Many of the NHS values are assessed in this station including some wider issues which address improving lives and commitment to quality of care.

Overall, the three MMI stations aim to 'assess' the student's values and their ability to communicate with different people; service users and carers, academic staff and professionals working in practice.

\section{Exploring values}

Prior to their first practice placement, students were divided into small groups to discuss what the NHS values mean to them as individuals. They were then asked to make pledges relating to their chosen NHS values which they would endeavour to embed into their practice whilst in a diagnostic imaging department. These pledges were written on Post-it notes and stuck to the Pledge wall (Figure 2). In sharing their pledges with each other, the students were encouraged to make these commitments to their peers.

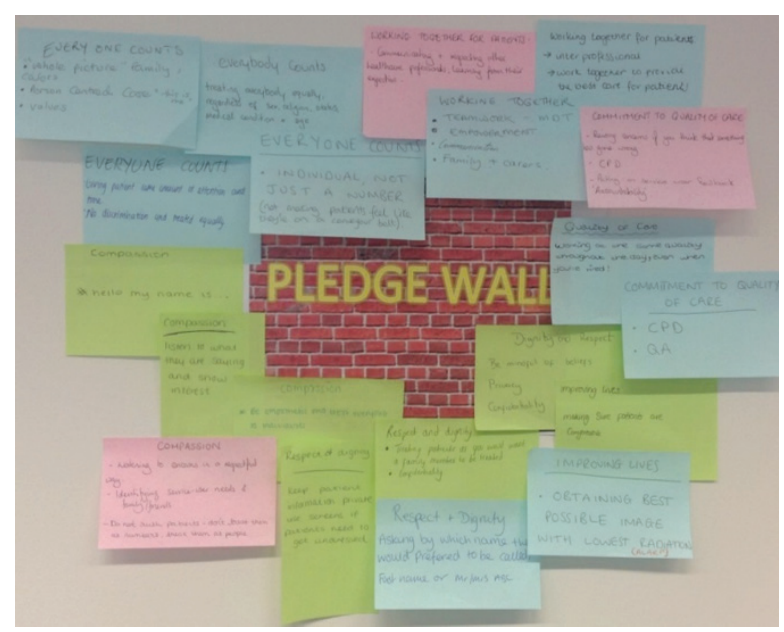

Figure 2: The Pledge Wall

Following this session, the educators collated the pledges and they were aligned to each of their corresponding NHS Values. The outcome of this evaluation is seen in Figure 3.

81 J. of Practice Teaching \& Learning 17(2), pp.78-90. ๑ w\&-b 
Hollie Hadwen, Jane Harvey-Lloyd, and Ruth Strudwick

\begin{tabular}{|c|c|}
\hline NHS Value & Pledges made by student radiographers \\
\hline $\begin{array}{l}\text { Working } \\
\text { together for } \\
\text { patients }\end{array}$ & $\begin{array}{l}\text { Respect everyone's views and include all team members } \\
\text { Communicate effectively in the team } \\
\text { Leave detailed notes for other members of the team } \\
\text { Learn from other healthcare professional's expertise } \\
\text { Communicate effectively with the patient's family and carers }\end{array}$ \\
\hline Compassion & $\begin{array}{l}\text { Introduce myself, use the 'Hello my name is...' campaign } \\
\text { Listen and show interest in the patient's concerns and feelings } \\
\text { Be empathetic } \\
\text { Give clear explanations to patients }\end{array}$ \\
\hline Improving lives & $\begin{array}{l}\text { Help diagnose fractures and illness to enable treatment } \\
\text { Observe As Low As Reasonably Practicable (ALARP) principle } \\
\text { Be aware of support groups and services available to patients } \\
\text { Undertake research and consider alternatives }\end{array}$ \\
\hline $\begin{array}{l}\text { Respect and } \\
\text { dignity }\end{array}$ & $\begin{array}{l}\text { Ask the patient what they want to be called e.g. first name or } \mathrm{Mr} / \\
\text { Mrs } \\
\text { Maintain confidentiality of patient information } \\
\text { Use screens if patients need to get undressed } \\
\text { Treat patients how I would expect to be treated } \\
\text { Treat patients as I would want my family member to be treated } \\
\text { Respect the patient's choices and beliefs } \\
\text { Keep personal opinions at home }\end{array}$ \\
\hline $\begin{array}{l}\text { Commitment to } \\
\text { quality of care }\end{array}$ & $\begin{array}{l}\text { Ensure I keep patients safe } \\
\text { Work to a high standard throughout the day, even when I'm tired } \\
\text { Seek and act upon patient feedback } \\
\text { Put what I have learned in lectures into practice } \\
\text { Undertake continuing professional development (CPD) } \\
\text { Make sure the patient understands what is going to happen } \\
\text { Uphold the Trust's values } \\
\text { Raise concerns if I think that something has gone wrong }\end{array}$ \\
\hline Everyone counts & $\begin{array}{l}\text { Treat everyone equally, regardless of gender, religion, status, } \\
\text { medical condition or age } \\
\text { I will celebrate colleague's successes } \\
\text { I will thank other members of the team } \\
\text { Treat people as individuals } \\
\text { Use 'This is me' scheme for patients with dementia } \\
\text { Won't let patients feel like they are on a conveyor belt }\end{array}$ \\
\hline
\end{tabular}

Figure 3 summarises the pledges made, and links them to the corresponding NHS value (Hadwen et al., 2016).

Upon returning to university, lecturers explored the students' reflections of their first practice placements and the extent to which they felt they had been able to uphold their pledges. This was undertaken as part of a module

82 J. of Practice Teaching \& Learning 17(2), pp.78-90. (C) w\&b 
evaluation and therefore ethical approval was not required

Hendry (2019) argues that lecturers can promote compassion through facilitated discussion of such reflections and the data collated during this reflective discussion focussed upon the areas that students enjoyed within their first placement, aspects of practice which appeared to align with the NHS values. Again, the students used Post-it notes to anonymously record their reflections, which were then thematically analysed by two of the authors. The framework by Braun and Clark (2006) was utilised to undertake the analysis and the most prominent values demonstrated were:

\section{Compassion}

Students described enjoying 'helping patients', 'communicating with patients' and 'having good conversations with patients', recognising the need for kindness and communication. Interestingly, students also acknowledged that patients were compassionate too, with one student noting that 'patients were a lot more grateful and patient than I expected, they didn't mind if you were slower'.

\section{Working together for patients}

Students enjoyed 'working and learning with radiographers', relishing the opportunity to work in 'multiple teams within the hospital', with frequent mention of positive experiences in the Emergency Department and operating theatres. Students valued the sense of 'being part of the team' at this early stage, appreciating the opportunity to 'get stuck in'. In addition to being taught by radiographers and second year students, one student recognised that they were also 'learning from patients', acknowledging the unique perspective of the service user and aligning with the NHS value of 'Everyone counts'.

\section{Respect and dignity}

It was evident that students had appreciated the diverse range of service users who access imaging services, stating that they enjoyed being 'able to

83 J. of Practice Teaching \& Learning 17(2), pp.78-90. ๑ wE-b 
get involved with different patient groups', 'the diversity of patients' and the 'variety of patient contact'.

It was apparent that students felt confident that they had triumphed in upholding many of the pledges made, but identified the limited time available with each service user as the biggest challenge.

\section{Discussion}

'There were found to be three main influences of the curriculum of the development of values-based practice. These were curriculum design, preparation for practice and the impact of practice.

\section{Curriculum design}

As previously acknowledged, the curriculum is designed to support students in cultivating their professional identity and values, as they develop into their new professional role. Whilst focussed upon the nursing profession, the Shape of Caring review (Health Education England, 2015) emphasised the role of lecturers and universities developing such curricula (McLean, 2012; Rankin, 2013).

There are two streams within the curriculum where NHS values are embedded, each complemented by service user involvement in teaching, learning and assessment. The diagnostic radiography modules include Working in Healthcare (level 4), The Service User (level 5) and Becoming the Professional (level 6).

During the Working in Healthcare module, students are introduced to a range of influential factors which will underpin their professional role. Students are encouraged to consider the NHS values within the context of their role as a student radiographer and undertake a range of workshops to fully explore the impact of these values on their future practice.

The module Becoming the Professional provides the opportunity for students in their final year to reflect on their learning thus far and to identify areas that they need to work on during their last placement. The NHS values are integral to the delivery of this module where we challenge the students to start thinking about being new graduates and taking responsibility for

84 J. of Practice Teaching \& Learning 17(2), pp.78-90. ๑ w\& b 
their own caseload of service users. Issues of communication, teamwork and person-centred care are all considered in depth from the perspective of a registered healthcare professional. Skills such as teaching and supervision of other staff, motivating and leading others and coaching are all explored in order to prepare students for transition into their role as a diagnostic radiographer.

The other stream within the curriculum is interprofessional learning, incorporating three modules; Working With Others (level 4), The Service User (level 5) and The Professional in the Team (level 6). A staff and student evaluation of the interprofessional learning programme has shown that the positive culture of interprofessional education entrenched within the HEI, enables students to work together for the benefit of the service user, underpinning compassionate and person-centred care (Strudwick et al., 2019).

During the interprofessional learning modules, students are encouraged to learn with, from and about one another in order to improve collaboration and the quality of care (CAIPE, 2008). Students use case studies involving different service users to learn how to care for service users as an interprofessional team and to develop their own values as health and social care professionals.

Service users share their experiences with students during both the interprofessional learning module and the diagnostic radiography module of the same name. Students are able to interact with different service users and understand their experiences of health and social care services. For example during the 2019 delivery of these modules, service users living with multiple sclerosis, Parkinson's disease, bowel cancer and mental health issues shared their experiences. The value of students learning from service users' stories in higher education is well recognised within contemporary literature (Christiansen et al., 2015; Harvey-Lloyd and Strudwick, 2018; Hendry, 2019).

The recently developed and published Values-based Practice in Diagnostic and Therapeutic Radiography training manual has also been used during sessions (The Association of Radiography Educators, The College of Radiographers and The Collaborating Centre for Values-based Practice in Health and Social Care, 2018). This underpins a range of workshops designed to prompt students to consider what service users value when visiting the imaging department.

During the third year interprofessional learning module students work in interprofessional teams to look at a family case study and consider their

85 J. of Practice Teaching \& Learning 17(2), pp.78-90. ๑ w\&-b 
input into the care of the different family members. This prepares them for working alongside other professionals for the benefit of the service user and how they can work towards respecting their values.

\section{Preparation for the first practice placement}

It is evident that the lecturer plays a crucial role in promoting student awareness in the academic setting, not only through the design and delivery of the curriculum, but a variety of strategies including role modelling (Hendry, 2019). Students adopt the norms, values and beliefs of the profession and find professional role models to emulate (Colley et al., 2003).

Students feel 'under pressure' from staff in the busy practice environment. Previous research has shown that the transition into practice can be challenging for students (Dare et al., 2009). Students spend two months in academic and start placement mid-November after an initial academic block in which time is spent preparing students for what they may experience during placement. Caring skills, communication skills, mandatory training, as well as the practical skills needed to undertake plain radiography are covered. They attend two evening sessions at the local hospital where they practice positioning one another for X-ray examinations and become familiar with the X-ray equipment. During their two months at university before placement, they also attend two one-day practice visits.

On the last day at University before the students go out for their first practice placement, there is a 'Practice Issues Day', which is run jointly by the university lecturers and the practice educators. All of the practice assessment documents are looked at again, expectations including professionalism, uniform policy and behaviour on placement are discussed. Students are given the opportunity to ask questions and to discuss their 'hopes and fears' for their future placement. Students are also able to discuss service users and scenarios in a safe, non-judgemental environment

\section{The impact of practice}

From the outset, students are encouraged to take ownership of their practice and be accountable for their behaviour, characteristics of a professional.

The practice educators, mentors and supervising radiographers that students work with from the start of the course are role models for students

86 J. of Practice Teaching \& Learning 17(2), pp.78-90. ๑ w\&bb 
and students learn about how to behave and what expected behaviour is. The behaviour of radiographers is governed by their professional culture. Ogbonna and Harris (2002) define culture as 'the collective sum of beliefs, values, meanings and assumptions that are shared by a social group and that help to shape the ways in which they respond to each other and their external environment' (p34). Crotty (2005) sees culture as the source of human thought and behaviour, suggesting that culture teaches us how to see things. Culture is about how members of a group interpret the world around them by developing shared understandings, it provides people with rules about how to operate in the world in which they live and work (Rubin and Rubin, 1995).

How employees become a part of the culture and how they learn to take on their professional role is an aspect of organisational culture. It is interesting to look at how people become socialised into their profession. Lave and Wenger (1991) discuss professional socialisation and how a newcomer joins a community of practice. Howkins and Ewens (1999) in their empirical study amongst community nursing students define professional socialisation as learning during education and training, the values, behaviours and attitudes necessary to assume the professional role, and knowing and understanding the profession. It involves acquiring knowledge which produces the correct conduct and allows others from the profession to recognise them as competent. One of the key aspects is role modelling. Lewis and Robinson (2003) carried out a study in Australia to gain a greater understanding of role modelling in diagnostic and therapeutic radiography. They found that professional growth was shaped and influenced by behavioural models accepted in the workplace and identifying of role models and positive attributes are important parts of professionalisation. Role models can demonstrate desirable skills and positive professional characteristics; senior staff can therefore influence the attitudes of junior staff and the perpetuation of behaviour. Lewis and Robinson (2003) assert that creation of positive role models is essential for professional growth in radiography.

Radiographers, like other healthcare practitioners, develop a pattern of working which perpetuates and becomes learnt behaviour, so that newcomers to the profession pick up this particular way of doing things and the behaviour continues and perpetuates. Radiography students become socialised into their profession and develop professional traits and norms and these become 'the way things are done'. However, it may also be the case that a professional network could be detrimental to the development

87 J. of Practice Teaching \& Learning 17(2), pp.78-90. ๑ w\&b 
of the profession. This could occur if practice was not challenged by others resulting in the perpetuation of poor practice and resistance to any suggestion of change (Southon, 2006).

There is evidence to suggest that students very quickly become socialised into the professional culture of practice (Holland 1993; Colley et al., 2003; Lewis and Robinson, 2003). In committing pledges, students are facilitated in exploring their own values and beliefs before they enter the practice placement and the established culture that exists within imaging departments, protecting them from influence.

\section{Conclusion}

There is no doubt that HEIs play a vital role in developing radiographers of the future and this ultimately begins with the recruitment and selection of students who demonstrate some knowledge and understanding of the NHS Values. It is then the responsibility of the HEI to explore and develop through the design of innovative curricula which consists of a range of activities. There are two pertinent areas of the curriculum which play a pivotal role; the radiography and interprofessional modules already discussed. The radiography modules encourage the students to explore their own values against those of the NHS and prior to the first placement explore those that they feel are most important to work towards during this time. On returning from practice their reflections underpin their professional development within the context of their chosen profession. In this study, it was apparent that the transient nature of the radiographer-service user relationship meant that time was the biggest challenge for students seeking to uphold their pledges in practice.

However, the interprofessional modules use case studies to explore these values further and to begin to challenge them. This 'real' experience of interprofessional working within the HEI, enables students to begin to face some of the barriers and challenges to interprofessional working that are inherent in contemporary professional practice.

Working in interprofessional groups allows students to learn from and about other professionals, it equips them with knowledge about other professional roles and enables them to work together with other members of the interprofessional team in the safety of the university setting. In this case they also learn about the values of each profession which underpin

88 J. of Practice Teaching \& Learning 17(2), pp.78-90. ๑ wE-b 
their role and also how when working together there are times, when compromises need to be reached. This fundamentally underpins true interprofessional working and enables students to work with one another for the good of their service users, as a result they start to become more compassionate and person-centred professionals.

\section{References}

CAIPE (2008) www.caipe.org.uk/about-us/defining-ipe

Christiansen A, O'Brien MR, Kirton JA, Zubairu K and Bray L (2015) Delivering compassionate care: the enablers and barriers. British Journal of Nursing, 24, $16,833-837$

Colley H, James D, Tedder M and Diment K (2003) Learning as becoming in vocational education and training: class, gender and the role of vocational habitus. Journal of Vocational Education and Training, 55, 4, 471-496

Crotty M (2005) The Foundations of Social Research - Meaning and Perspective in the Research Process. London: Sage

Dare A, Fancourt N, Robinson E, Wilkinson T and Bagg W (2009) Training the intern: the value of a pre-intern year in preparing students for practice. Medical Teacher, Web paper, 2009; 31; e345-350

Department of Health (DH) (2015) The NHS Constitution: The NHS belongs to us all. London: The Stationery Office

Fulford K.W.M, Peile E and Carroll H (2012) Essentials of Values-based Practice: Clinical stories linking science with people. Cambridge: Cambridge University Press

Hadwen H, Strudwick R \& Harvey-Lloyd J (2016) Values-based radiography. Imaging \& Therapy Practice, November, 25-29

Harvey-Lloyd JM and Strudwick RM (2018) Embracing diversity in radiography: The role of service users. Radiography 24 (Supp 1), S16-S19

Health Education England (2015) Raising the Bar: Shape of Caring: A Review of the Future Education and Training of Registered Nurses and Car Assistants. Online at: https://www.hee.nhs.uk/sites/default/files/documents/2348-Shape-of-caring-reviewFINAL.pdf [Accessed on: 30 January 2020]

Hendry J (2019) Promoting compassionate care in radiography - What might be suitable pedagogy? A discussion paper. Radiography, 25, 3, 269-273

Holland C K (1993) An ethnographic study of nursing culture as an explanation for determining the existence of a system of ritual. Journal of Advanced Nursing,18, $1461-1470$

89 J. of Practice Teaching \& Learning 17(2), pp.78-90. ๑ wE-b 
Howkins E J and Ewens A (1999) How students experience professional socialisation. International Journal of Nursing Studies, 35, 41-49

Lave J and Wenger E (1991) Situated learning. Legitimate peripheral participation. Cambridge: Cambridge University Press

Lewis S J and Robinson J W (2003) Role model identification by medical science practitioners - A pilot study. Radiography, 9, 13-21

McClean C (2012) The Yellow Brick Road: a values based curriculum model. Nurse Educ Pract 12, 3, 159-63. Doi: 10.1016/j.nepr.2011.11.002. Epub 2011 Dec9

Ogbonna E and Harris L C (2002) Managing organisational culture: insights from the hospitality industry. Human Resource Management Journal, 12, 1, p33-53

Rankin B (2013) Emotional intelligence: enhancing values-based practice and compassionate care in nursing. Journal of Advanced Nursing. 2013 Dec; 69(12):2717-25. Doi: 10.111/jan.12161. Epub 2013 Apr 28

Rubin H J and Rubin I S (1995) Qualitative Interviewing - The Art of Hearing data. Sage, Thousand Oaks

Southon G (2006) The role of professional networks in radiology services. Rev Panam Salud Publica 2006, 20, 2/3, 99-103

Strudwick R M, Harvey-Lloyd J M \& Hadwen H C (2019) The Role of Interprofessional Learning in Developing Transformative Health \& Social Work Professionals. The Journal of Practice Teaching and Learning, 16, 1, p96-108

The Association of Radiography Educators, The College of Radiographers and The Collaborating Centre for Values-based Practice in Health and Social Care (2018). Values-based Practice in Diagnostic and Therapeutic Radiography: A Training Template [online] [Date accessed]. Available from: https://www.sor. org/sites/default/files/document-versions/2018.10.03_radiography_vbp_training_ manual___final.pdf

90 J. of Practice Teaching \& Learning 17(2), pp.78-90. ๑ w\& b 